\title{
PERANCANGAN MAXIMUM POWER POINT TRACKING PADA PEMBANGKIT LISTRIK TENAGA BAYU MENGGUNAKAN FOUR SWITCH BUCK BOOST CONVERTER DENGAN METODE P\&O-ORB
}

\author{
Machmud Effendy*), Rosyadi Nur Syahputra, dan Khusnul Hidayat \\ Jurusan Teknik Elektro, Fakultas Teknik, Universitas Muhammadiyah Malang \\ Jl. Raya Tlogomas 246 Malang, 65144, Indonesia \\ ${ }^{*}$ E-mail: machmud@umm.ac.id
}

\begin{abstract}
Abstrak
MPPT (maximum power point tracking) merupakan cara untuk memaksimalkan daya keluaran pada pembangkit listrik tenaga bayu (PLTB). Sistem MPPT pada PLTB terdiri dari DC-DC converter dan metode kontrol. Pada penelitian ini, sistem MPPT menggunakan Four Switch Buck Boost (FSBB) converter, dimana converter ini memiliki polaritas tegangan yang sama antara input dan output, ripple tegangan rendah, dan efisiensi daya lebih besar dibandingkan dengan Buck Boost Converter. Metode kontrol yang digunakan adalah Perturb and Observe ( $\mathrm{P} \& \mathrm{O})$ - ORB (Optimum Relations-Based) yang memiliki tingkat osilasi lebih rendah dan efisiensi lebih tinggi dibandingkan dengan metode P\&O. Sistem MPPT disimulasikan menggunakan software PSIM untuk mengetahui performa P\&O-ORB dan FSBB converter. Evaluasi kinerja P\&O-ORB dan FSBB diuji dalam kondisi kecepatan angin $5 \mathrm{~m} / \mathrm{s}$. Hasil simulasi menunjukkan FSBB memiliki tingkat kesalahan yang lebih kecil daripada Buck Boost yaitu 0,02\%. Dan sistem MPPT dengan metode P\&O-ORB memiliki tingkat efisiensi yang tinggi mencapai 98,04\%.
\end{abstract}

Kata kunci: MPPT, P\&O, ORB, Four Switch Buck Boost

\begin{abstract}
MPPT (maximum power point tracking) is a technique of maximizing power in wind power plants. The MPPT consists of a DC-DC converter and a control method. In this study, the MPPT system uses a Buck Four Boost Converter (FSBB) converter, where the converter has the same voltage polarity between input and output, low voltage ripple, and greater power efficiency compared to Buck Boost Converter. The control methods used are Perturb and Observe (P \& O) - ORB (Optimal Relationship Based) which have lower oscillation rates and higher efficiency compared to the $\mathrm{P} \& \mathrm{O}$ method.The MPPT system was simulated using PSIM software to determine the performance of P\&O-ORB and FSBB converter. Evaluate the performance of P\&O-ORB and FSBB values in wind speeds of $5 \mathrm{~m} / \mathrm{s}$. Simulation results show FSBB has a smaller error rate than Buck Boost which is $0.02 \%$. And the MPPT system with the P \& O-ORB method has higher power efficiency compared to the $\mathrm{P} \& \mathrm{O}$ method which is equal to $98.01 \%$.
\end{abstract}

Keywords: MPPT, P\&O, ORB, Four Switch Buck Boost.

\section{Pendahuluan}

Pada era saat ini sangat dibutuhkan energi terbarukan sebagai energi alternatif untuk pembangkit listrik. Hal ini disebabkan karena persediaan sumber daya alam tak terbarukan seperti bahan bakar fosil seperti gas alam, minyak bumi dan batu bara sudah mulai menipis persediaanya serta diperlukan juga sumber energi yang eco-friendly untuk mencegah terjadinya global warming dan mengurangi polusi udara serta menjaga alam lingkungan di sekitarnya. Salah satu energi terbarukan adalah energi angin atau bayu. Indonesia sebagai negara berkepulauan memiliki rata-rata kecepatan angin yang besar yaitu $5 \mathrm{~m} / \mathrm{s}[1]$. Dengan melihat potensi tersebut maka energi angin cukup handal untuk dijadikan sumber energi pembangkit listrik.

Salah satu kelemahan pembangkit listrik tenaga bayu adalah sering terjadi fluktuasi kecepatan angin sehingga diperlukan sebuah sistem untuk menghasilkan daya maksimal saat kecepatan angin tidak konstan[2]. Efisiensi konversi energi turbin angin akan maksimal jika perbandingan antara kecepatan angin dan kecepatan ujung sudu semakin tinggi. Sedangkan transisi kecepatan angin harus disertai dengan perubahan kecepatan rotor turbin angin untuk mempertahankan kecepatannya pada titik optimal[3]. Berdasarkan hasil penelitian sebelumnya, untuk mengoptimalkan daya keluaran turbin angin, sistem pembanglit listrik perlu dilengkapi MPPT. Terdapat 
berbagai jenis metode untuk mendapatkan titik operasi maksimum dari sistem turbin angin, diantaranya adalah kendali tip speed ratio (TSR), hill climbing search atau P\&O, kendali power signal feedback (PSF)[4]. Metode $\mathrm{P} \& \mathrm{O}$ dikenal lebih fleksibel dan mudah akan tetapi kurang efisien dan bisa bermasalah jika menentukan step size yang kurang sesuai [5]. Metode $\mathrm{P} \& \mathrm{O}$ merupakan metode yang sederhana dan mudah diterapkan dibandingkan dengan metode lainnya. Namun, metode ini memiliki beberapa kekurangan yaitu tingkat osilasi tinggi dan efisiensi yang diperoleh dari metode ini tergantung pada ukuran variabel step-size $(\Delta \mathrm{D})$, sehingga waktu yang dibutuhkan untuk mencapai nilai maksimal cukup lama [6]. Sedangkan metode ORB lebih cepat dalam menemukan titik maksimal daya PLTB, namun membutuhkan ketepatan nilai parameter inisialisasi, dimana secara praktek sulit untuk didapatkan.

Sistem MPPT juga membutuhkan rangkaian dc-dc konverter yang mampu mengurangi rugi-rugi daya. Terdapat berbagai jenis dc to dc konverter seperti BuckBoost, Zeta, SEPIC dan CUK konverter. FSBB converter merupakan pengembangan dari buck boost conveter. Dimana FSBB memiliki kelebihan antara lain efisiensi daya lebih tinggi karena penggantian komponen diode menjadi transistor dan nilai resistansi dalam saat terjadi proses switching lebih kecil. Pada penelitian sebelumnya diklaim bahwa FSBB bisa mendapatkan tingkat efisiensi daya antara 96,5\% hingga 97,8\% [7].

Untuk mengatasi kelemahan metode $\mathrm{P} \& \mathrm{O}$ dan ORB, maka dalam penelitian ini, kedua metode digabung menjadi metode baru yaitu P\&O-ORB. Dan untuk mengurangi rugi-rugi daya listrik converter, digunakan FSBB converter.

\section{Metode}

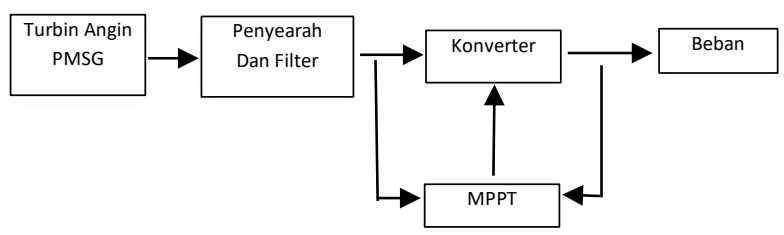

Gambar 1. Blok Diagram Sistem

Tahap pertama dirancang model sistem MPPT dengan diagram sistem sebagaimana ditunjukkan pada Gambar 1. Turbin angin dihubungkan dengan PMSG (Permanent Magnet Synchronous Generator untuk membangkitkan daya listrik. Keluran tegangan PMSG yang masih AC diumpankan ke rangkaian penyearah untuk dijadikan tegangan DC. Untuk mengurangi ripple tegangan DC, maka diperlukan rangkaian filter kapasitor. Setelah melalui filter akan diteruskan ke DC-DC konverter jenis FSBB. Rangkaian FSBB diatur melalui metode algoritma P\&OORB melalui pembacaan sensor arus dan tegangan PMSG. Keluaran MPPT berupa sinyal duty cycle yang akan membuat komponen mosfet dalam FSBB menjadi On dan Off.

\subsection{Turbin Angin dan PMSG}

Simulasi turbin angin dan PMSG menggunakan perangkat lunak PSIM 9.1. Turbin angin dan PMSG memiliki parameter yang ditunjukkan pada Tabel 1 dan 2 .

Tabel 1. Parameter Turbin Angin

\begin{tabular}{cc}
\hline Parameter & Nilai \\
\hline Nominal Output Power & $40 \mathrm{~kW}$ \\
Base Rotational Speed & $1000 \mathrm{Rpm}$ \\
Moment of Inertia & $0.0079 \mathrm{kgm}^{2}$ \\
\hline
\end{tabular}

Tabel 2. Parameter PMSG

\begin{tabular}{cc}
\hline Parameter & Nilai \\
\hline Stator Resistance (Rs) & $0.4 \mathrm{Ohm}$ \\
Ld(d-axis ind.) & $5.4 \mathrm{mH}$ \\
Lq (q-axis ind.) & $5.4 \mathrm{mH}$ \\
No of Poles & 4 \\
Moment of Inertia & $0.0079 \mathrm{kgm}^{2}$ \\
\hline
\end{tabular}

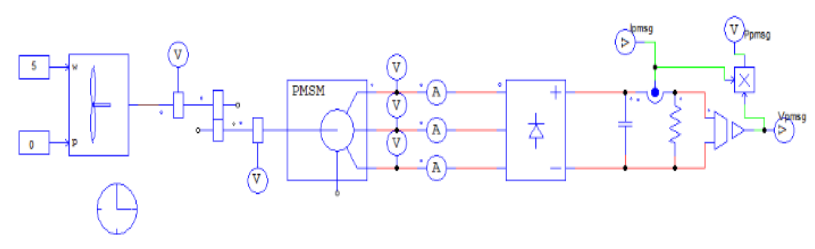

Gambar 2. Simulasi Turbin Angin dan PMSG

Gambar 2 menunjukkan bahwa terdapat dua macam masukan turbin angin yaitu kecepatan angin dan sudut bilah turbin. Pada penelitian ini digunakan sudut bilah $0^{0}$. Kemudian masukan diteruskan ke sensor kecepatan dan gear box sebelum memasuki PMSG. Keluaran dari PMSG dihubungkan dengan penyearah tiga fasa, setelah itu dihubungkan ke filter yang berupa kapasitor dan ke beban berupa resistor. Keuntungan menggunakan PMSG adalah stabilitas dan konstan dalam hal tegangan dan arus, biaya perawatan yang cukup rendah, resistensi yang tinggi membuat generator ini cocok untuk pembangkit listrik turbin angin skala kecil [8].

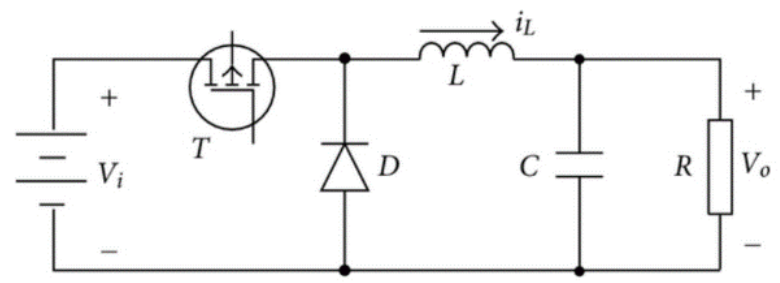

Gambar 3. Rangkaian Konverter Buck Boost

\subsection{Konverter Buck Boost}

Gambar 3 menunjukkan rangkaian dasar converter Buck Boost yang mampu menaikkan dan menurunkan tegangan 
DC. Rangkaian ini memerlukan pulsa PWM untuk membuat kondisi saturasi dan cut off pada komponen MOSFET. Tegangan keluaran konverter yang dikehendaki sebesar 62,97 V dengan perubahan nilai tegangan masukan antara 40,82- 73,78 V. Agar kriteria tersebut dapat terpenuhi maka besarnya lebar pulsa atau duty cycle didapatkan melalui persamaan (1) [9]

$$
\frac{V o}{V i n}=\frac{D}{1-D}
$$

$$
\begin{array}{ll}
D_{\text {max }}=\frac{62,97}{103,79} & D_{\text {min }}=\frac{62,97}{136,75} \\
D_{\text {max }}=0,6066 & D_{\text {min }}=0,4604
\end{array}
$$

Nilai minimal untuk induktor dapat ditentukan dengan menggunakan nilai duty cycle diaplikasikan ke dalam persamaan (2)

$L_{\min }=\frac{(1-D)^{2} \cdot R}{2 f}$

$L_{\text {min }}=\frac{(1-0,4604)^{2} \cdot 2,72}{2.100000}=3,95907 u H$

Nilai minimal untuk kapasitor dapat ditentukan dengan menggunakan ripple sebesar $1 \%$ diaplikasikan ke dalam persamaan (3)

$$
\begin{aligned}
C_{\text {min }} & =\frac{D}{R\left(\frac{\Delta V_{o}}{V_{o}}\right) f} \\
C_{\text {min }} & =\frac{0,6066}{2,72(0,01) 100000}=223,045 \mathrm{uF}
\end{aligned}
$$

\subsection{Konverter Four Switch Buck Boost}

Gambar 4 menunjukkan rangkaian Four switch buck boost konverter yang terdiri dari empat saklar elektronik mosfet. Konverter ini dapat beroperasi dalam mode buck, boost, dan buck boost. Setiap mode memerlukan 1 mosfet yang dikontrol oleh duty cycle sedangkan mosfet lainnya adalah untuk komutasi dan dikontrol dengan duty cycle berkebalikan dengan pasangannya. Sedangkan mosfet lainnya diatur dalam posisi tetap.

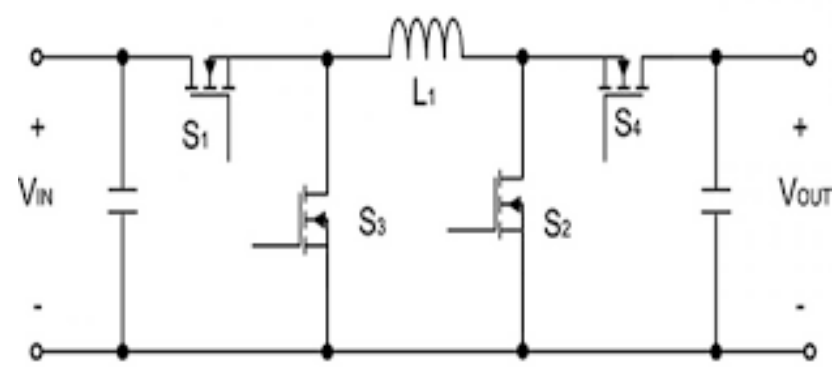

Gambar 4. Rangkaian Konverter Four Switch Buck Boost
FSBB merupakan gabungan dari buck konverter dan diikuti oleh sebuah boost konverter. Output dari rangkaian ini memiliki output yang tidak terbalik, yaitu polaritas tegangan input dengan output sama yang merupakan salah satu keunggulan FSBB dari topology lainnya seperti cuk, buck-boost yang memiliki output tegangan berkebalikan dengan input. Keunggulan lainnya adalah dengan desain hanya sebuah induktor maka ukurannya bisa menjadi lebih kecil dan rugi yang lebih sedikit dibandingkan dengan topology lainnya yang menggunakan 2 induktor seperti CUK, SEPIC, dan ZETA konverter [10].

Rangkaian ini memerlukan pulsa PWM untuk membentuk kondisi saturasi dan cut off komponen MOSFET. Tegangan keluaran konverter yang dikehendaki sebesar $62,97 \mathrm{~V}$ dengan perubahan nilai tegangan masukan antara 40,82- 73,78 V. Agar kriteria tersebut dapat terpenuhi maka besarnya lebar pulsa atau duty cycle didapatkan melalui persamaan (1) dan nilai minimal untuk kapasitor dapat ditentukan dengan persamaan (3) dimana Dmin = 0,4604, Dmax $=0,6066$ dan $\mathrm{Cmin}=223,045 \mu \mathrm{F}$.

Nilai minimal untuk induktor dapat ditentukan dengan menggunakan nilai duty cycle diaplikasikan ke dalam persamaan berikut:

$I_{L}=\frac{I_{o u t}}{1-D}$

$I_{L}=\frac{I_{\text {out }}}{1-D}=\frac{23,11}{1-0,4604}=42,8323 \mathrm{~A}$

$\Delta I_{L}=0,3 \times I_{L}$

$\Delta I_{L}=0,3 \times I_{L}=0,3 \times 42,8323=12,8497 \mathrm{~A}$

$L_{\min }=\frac{V_{\text {in }} \cdot D}{f \cdot \Delta I_{L}}$

$L_{\min }=\frac{V_{i n \cdot D}}{f \cdot \Delta I_{L}}=\frac{73,786 \cdot 0,4604}{100000 \cdot 12,8497}=26,4403 u H$

\subsection{Pemodelan P\&O-ORB}

Metode ini digunakan untuk melacak daya maksimum dari PMSG yang akan digunakan. Untuk pemodelan P\&OORB menggunakan algoritma yang diilustrasikan dalam bentuk flowchart pada gambar 5 .

Algoritma dimulai dengan menentukan nilai k awal yaitu 0 , kemudian nilai $\mathrm{P}$ treshold atau nilai ambang batas daya serta nilai step arus yang akan digunakan. Selanjutnya mengukur nilai tegangan dan arus pada sistem kemudian dihitung nilai dayanya dan selisih daya dengan daya sebelumnya. Kemudian jika k masih 0 maka akan masuk ke dalam mode $\mathrm{P} \& \mathrm{O}$ jika k sudah berisi nilai maka akan masuk ke dalam mode ORB. Dalam mode P\&O jika daya sekarang lebih kecil dari sebelumnya maka nilai sign akan menjadi -1 dan jika lebih besar maka nilai sign akan menjadi satu. Kemudian dibandingkan apakah selisih daya lebih kecil atau sama dengan ambang batas selisih daya 
yang ditentukan. Jika tidak, maka arus referensinya adalah arus referensi sebelumnya ditambah nilai sign yang dikali dengan step. Jika iya maka akan dihitung nilai $\mathrm{k}$ nya kemudian arus referensinya adalah nilai k dikali dengan nilai tegangan kuadrat.

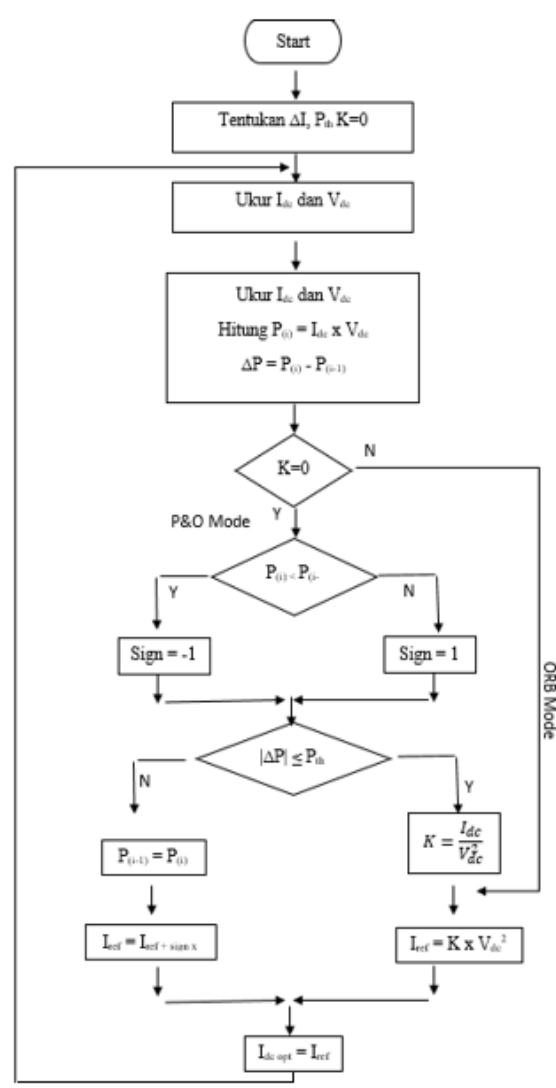

Gambar 5. Diagram alur algoritma P\&O-ORB

Nilai $\mathrm{k}$ dan arus referensi dapat didapatkan dengan persamaan berikut:[11,12]

$k=\frac{I_{d c-p e a k}}{V_{d c-p e a k}^{2}}$

$I_{\text {ref }}=K x V_{d c}^{2}$

Dalam algoritma ini, yang pertama terinisiasi yaitu mode P\&O karena nilai $\mathrm{k}$ nya belum ditemukan atau masih berupa 0 setelah nilai $\mathrm{k}$ ditemukan maka akan memasuki mode ORB dimana nilai $\mathrm{k}$ yang ditemukan tadi akan digunakan terus menerus. Untuk menentukan arus referensi awal diperlukan nilai acuan dari nilai arus untuk mencapai daya maksimum dari PMSG. Dalam pengujian ini digunakan nilai daya maksimum dari PMSG saat kecepatan angin $5 \mathrm{~m} / \mathrm{s}$.

\section{Hasil dan Analisis \\ 3.1. Pengujian Konverter Buck Boost}

Pengujian ini memerlukan pulsa generator sebagai pemicu pin gate pada komponen MOSFET di rangkaian dengan frekuensi sebesar $100 \mathrm{kHz}$ dan amplitudo 1V. Tegangan keluaran yang diinginkan $62,97 \mathrm{~V}$. Hasil pengujian seperti terlhat pada Tabel 3 .

Tabel 3. Hasil Pengujjian Konverter Buck Boost

\begin{tabular}{ccc}
\hline Tegangan Masuk (V) & Duty cycle (\%) & Tegangan Keluaran (V) \\
\hline 40 & 61,15 & $-63,043$ \\
50 & 55,74 & $-63,077$ \\
55 & 53,37 & $-63,080$ \\
60 & 51,20 & $-63,086$ \\
65 & 49,20 & $-63,094$ \\
75 & 45,64 & $-63,126$ \\
\hline
\end{tabular}

Tabel 3 menunjukkan bahwa konverter bekerja dengan baik dengan rata-rata error $0,18 \%$. Akan tetapi tegangan keluaran memiliki polaritas terbalik dengan tegangan masukannya.

\subsection{Pengujian Konverter Four Switch Buck Boost}

Pengujian ini memerlukan pulsa generator sebagai pemicu pin gate pada komponen mosfet di rangkaian dengan frekuensi $100 \mathrm{kHz}$ dan amplitudo $1 \mathrm{~V}$. Tegangan keluaran yang diinginkan $62,97 \mathrm{~V}$. Hasil pengujian seperti terlihat pada Tabel 4.

Tabel 4. Hasil Pengujian Konverter Four Switch Buck Boost

\begin{tabular}{ccc}
\hline $\begin{array}{c}\text { Tegangan } \\
\text { Masuk (V) }\end{array}$ & $\begin{array}{c}\text { Duty cycle } \\
(\%)\end{array}$ & $\begin{array}{c}\text { Tegangan } \\
\text { Keluaran (V) }\end{array}$ \\
\hline 40 & 61,15 & 62,967 \\
50 & 55,74 & 62,992 \\
55 & 53,37 & 62,992 \\
60 & 51,20 & 62,992 \\
65 & 49,20 & 62,993 \\
75 & 45,64 & 62,996 \\
\hline
\end{tabular}

Tabel 4 memperlihatkan bahwa konverter bekerja dengan baik dengan rata-rata error $0,02 \%$. Tegangan keluaran dari konverter sefase dengan tegangan masukan, berbeda dengan konverter Buck Boost.

Tabel 5. Hasil Pengujian Efisiensi Konverter Buck Boost dan FSBB

\begin{tabular}{cccccccc}
\hline Wind Speed & $\begin{array}{c}\text { Duty cycle } \\
(\mathrm{m} / \mathrm{s})\end{array}$ & \multicolumn{2}{c}{ Buck Boost } & \multicolumn{2}{c}{ FSBB } & \multicolumn{2}{c}{ Efisiensi (\%) } \\
\cline { 3 - 7 } & $(\%)$ & Pin & Pout & Pin & Pout & BB & FSBB \\
\hline 3 & & 579,1 & 502,2 & 572,4 & 522,3 & 86,7 & 91,2 \\
4 & & 940,3 & 818,7 & 935,6 & 858,1 & 87,0 & 91,7 \\
5 & 50 & 1273,8 & 1110,9 & 1277,3 & 1173,5 & 87,2 & 91,8 \\
6 & & 1557,6 & 1358,9 & 1572,9 & 1445,6 & 87,2 & 91,9 \\
7 & & 1789,4 & 1561,7 & 1817,8 & 1670,4 & 87,2 & 91,8 \\
\hline
\end{tabular}

Tahap selanjutnya menguji efisiensi daya kedua konverter dengan dihubungkan dengan PMSG. Pengujian ini menggunakan duty cycle $50 \%$ dengan frekuensi $100 \mathrm{kHz}$. Tabel 5 memperlihatkan bahwa FSBB memiliki tingkat efisiensi daya lebih tinggi sekitar 4,63\% dari Buck Boost dan FSBB memiliki tingkat error yang lebih kecil dari Buck Boost yaitu $0.02 \%$. 


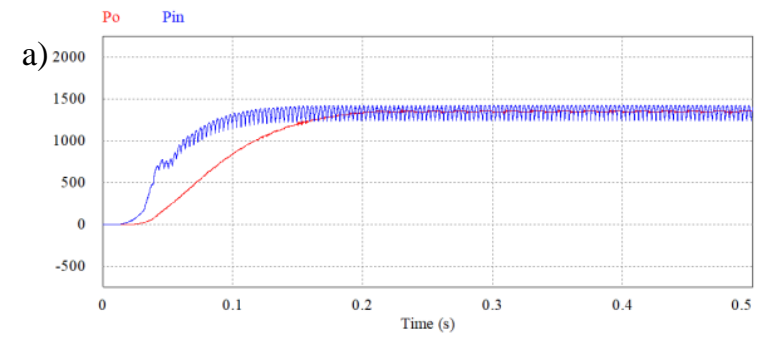

b)
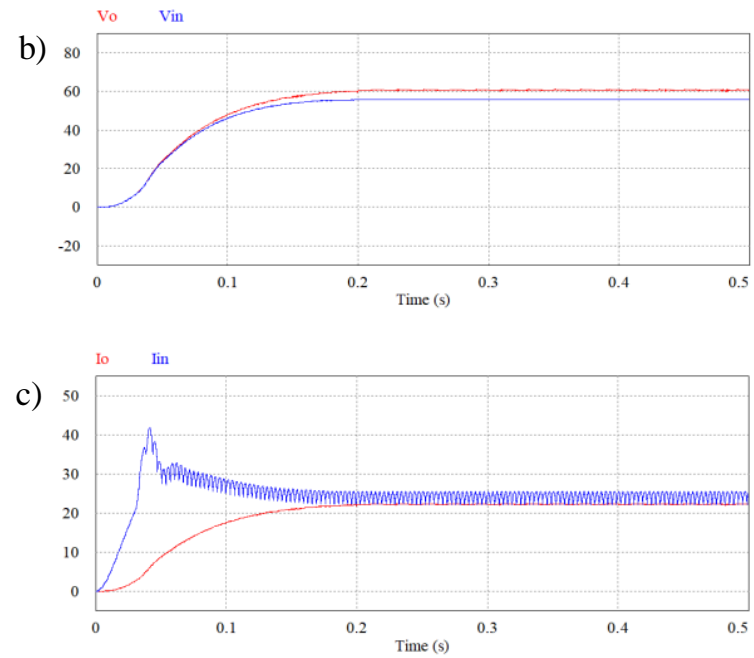

Gambar 6. a) Daya FSBB dengan P\&O, b) Tegangan FSBB dengan P\&O, dan c) Arus FSBB dengan P\&O
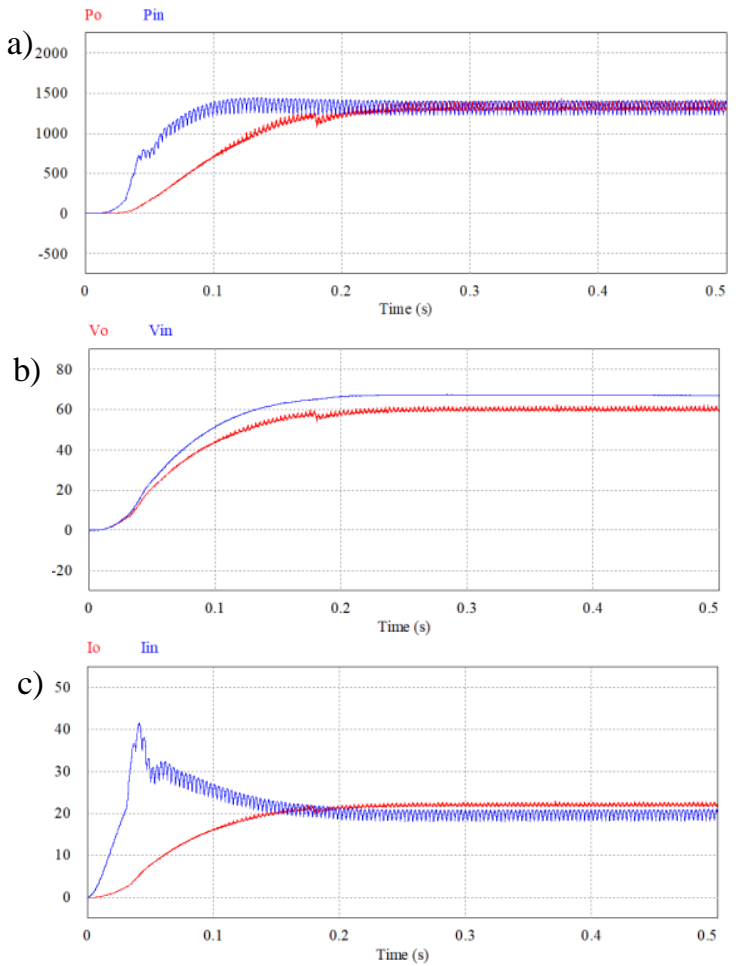

Gambar 7. a) Daya FSBB dengan P\&O-ORB, b)Tegangan FSBB dengan P\&O-ORB, dan c) Arus FSBB dengan P\&O-ORB

\subsection{Pengujian Sistem MPPT}

Masukan dari sistem MPPT adalah tegangan dan arus keluaran dari PMSG, sementara keluaran dari sistem MPPT ini merupakan duty cycle yang berubah-ubah yang digunakan untuk mengontrol rangkaian konverter Four Switch Buck Boost. Pada penelitian ini menggunakan kecepatan angin $5 \mathrm{~m} / \mathrm{s}$ untuk menggerakkan turbin angin. Untuk membandingkan performa antara P\&O (Perturb and Observe) konvensional dan $\mathrm{P} \& \mathrm{O}-\mathrm{ORB}$, daya keluaran dari PMSG dikontrol dengan kedua algoritma tersebut, sebagaimana hasilnya ditunjukkan dalam Gambar 6 dan 7.

Tabel 6. Hasil Perbandingan Pengujian MPPT P\&O dan P\&O-ORB

\begin{tabular}{cccccccc}
\hline $\begin{array}{c}\text { Jenis } \\
\text { MPPT }\end{array}$ & $\begin{array}{c}\text { Pin } \\
\text { (W) }\end{array}$ & $\begin{array}{c}\text { Pout } \\
\text { (W) }\end{array}$ & $\begin{array}{c}\text { Vin } \\
\text { (V) }\end{array}$ & $\begin{array}{c}\text { Vout } \\
\text { (V) }\end{array}$ & $\begin{array}{c}\text { lin } \\
(\mathbf{A})\end{array}$ & $\begin{array}{c}\text { lout } \\
(\mathbf{A})\end{array}$ & $\begin{array}{c}\text { Efisiensi } \\
(\%)\end{array}$ \\
\hline P\&O & 1312,89 & 1276,76 & 53,88 & 57,88 & 24,83 & 21,28 & 97,24 \\
P\&O-ORB & 1308,16 & 1282,57 & 63,67 & 56,99 & 21,03 & 20,95 & 98,04 \\
\hline
\end{tabular}

Tabel 6 memperlihatkan bahwa $\mathrm{P} \& \mathrm{O}$ memiliki daya input dan output rata-rata sebesar 1312,89 $\mathrm{W}$ dan 1276,76 W, sedangkan P\&O-ORB memiliki daya input dan output ratarata sebesar 1308,16 W dan 1282,57 W. Sehingga P\&OORB memiliki nilai efisiensi yang lebih baik jika dibandingkan dengan $\mathrm{P} \& \mathrm{O}$ konvensional. Hal ini disebabkan oleh efek mengubah nilai duty cycle terus menerus dari $\mathrm{P} \& \mathrm{O}$ konvensional. Perubahan ini mempengaruhi nilai daya output sehingga nilai berubah terus menerus sesuai dengan duty cycle yang ada. Sedangkan metode P\&O-ORB setelah nilai k ditemukan, nilai arus referensi akan diketahui sebagai duty cycle sehingga jika nilai arus input tidak berubah, algoritma akan mempertahankan nilai arus referensi.

\section{Kesimpulan}

Pelacakan titik daya maksimum dengan metode penggabungan antara $\mathrm{P} \& \mathrm{O}$ dan ORB diusulkan dalam makalah ini. Metode yang digunakan adalah dengan menerapkan MPPT yang dikendalikan oleh algoritma yang telah diusulkan dan menggunakan konverter FSBB untuk menjaga daya output PMSG pada titik maksimum. Dari hasil yang diperoleh dapat disimpulkan bahwa konverter FSBB memiliki tingkat efisiensi yang lebih tinggi sekitar 4,63\% dari Buck Boost dan FSBB memiliki tingkat kesalahan yang lebih kecil daripada Buck Boost yaitu $0,02 \%$. Selain itu, algoritma MPPT P\&O-ORB memiliki tingkat efisiensi $98,04 \%$ sedangkan $\mathrm{P} \& \mathrm{O}$ konvensional memiliki tingkat efisiensi 97,24\%. Dengan demikian, algoritma P\&O-ORB memiliki tingkat efisiensi yang lebih baik sebesar $0,8 \%$. 


\section{Referensi}

[1]. Tridianto E, Rizkidianto W. T, " "Maximum Power Point Tracking dengan Algoritma Perturb and Observation untuk Turbin Angin.” Jurnal Ilmiah SETRUM Vol.5 No.2, 2016.

[2]. G. V. Sadegh, H. Rastegar, and B. G. Gevork, A new three-mode maximum power point tracking algorithm for doubly fed induction generator based wind energy conversion system, Electric Power Component and System. Vol. 42 no. 1, hal. 45-59. 2013

[3]. Daili Y., Gaubert J.P., Rahmani . "Implementation of a new maximum power point tracking control strategy for small wind energi conversion systems without mechanical sensors", Energi Conversion and Management, vol. 97, hal. 298-306, 2015.

[4]. Daud, P. K., "Optimasi Pembangkit Listrik Tenaga Angin Menggunakan Maximum Power Point Tracking (MPPT) Dengan Metode Particle Swarm Optimazation.” Teknik Elektro, Univesitas Gajah Mada, 2016.

[5]. M. Otong, R.M. Bajuri, "Maximum Power Point Tracking (MPPT) Pada Sistem Pembangkit Listrik Tenaga Angin Menggunakan Buck-Boost Converter," Jurnal Ilmiah SETRUM - Volume 5, No.2, hal. 103-110, Desember. 2016.

[6]. Kumar D., Chatterjee K., "A review of conventional and advanced MPPT algorithms for wind energi systems", Renewable and Sustainable Energi Reviews, vol. 55, hal. 957-970, 2015.
[7]. X. Ren, X. Ruan, H. Qian, M. Li, Q. Chen, "Three-Mode Dual -Frequency Two-Edge Modulation Scheme for Four-Switch Buck-Boost Converter," IEEE Transactions On Power Electronics, VOL. 24, NO. 2, hal. 499-509. 2009.

[8]. Ernadi D. A., Pujiantara M., Purnomo M. H., "Desain Maximum Poer Point Tracking untuk Turbin Angin Menggunakan Modified Perturb and Observe (P\&O) Berdasarkan Prediksi kecepatan Angin”, Jurnal Teknik ITS Vol 5, No. 2, B265-B271, 2016.

[9]. Machmud Effendy., "Rancang Bangun Maximum Power Point Tracking (MPPT) Solar Sel Untuk Aplikasi Pada Sistem Grid Pembangkit Listrik Tenaga Angin (PLTAg)", Jurnal Gamma, Vol. 9, No. 1, hal. 170-178, 2013.

[10]. Taufik T, A. Justin, D. Dale, A. Makbul, "Comparative Study of 4 Switch Buck Boost Controller and Regular Buck Boost”, International Journal on Advanced Science, Engineering and Information Technology, vol. 1 no.4, hal. 441-446, 2011

[11]. Abdullah M.A., Yatim A. H. M., Tan C. W. “An Online Optimum Relations-Based Maximum Power Point Tracking Algorithm for Wind Energy Conversion System", In 2014 Australasian Universities Power Engineering Conference (AUPEC), pp. 1-6, 2014.

[12]. Rahim, A.H.M.A, "Optimum Relation Based Maximum Power Point Tracking of a PMSG Wind Generator Through Converter Controls", 7th IET International Conference on Power Electronics, Machines and Drives, 2014 